International Journal of Artificial Intelligence and Applications (IJAIA), Vol.10, No.2, March 2019

\title{
AN OBNOXIOUS LACUNA ON DISCOURSES AND COUNTER DISCOURSES OVER ARTIFICIAL INTELLIGENCE
}

\author{
Dr. Atindra Dahal \\ Associate Professor, Kathmandu School of Law, Bhaktapur, Nepal
}

\begin{abstract}
Artificial intelligence is the highest form of human development and sound outcome of human conscience till the date. But the very development seems to be devastating to human future ahead and has been heavily projected accordingly. More than it may be to decay and destroy the world, the negative and chilling views on the prospective damages of AI that scholars are percolating to public are costing many times on humans; and that is plunging human mindset into irreparable pessimism and negativity. This article explores the way that AI is being depressingly explored and investigated to browbeat public. In addition, this write-up highlights the serious lacuna, which the advanced academic engagement has still grossly failed to fill up, of a great deal in course of mainstreaming views and discussions for noble cause of human development and societal well-belling . Further, it unmasks the dire need in making constructive, encouraging and optimistic mind-set building academic pursuits and writings then makes an alarming call to the all prominent scholars to engage with due compliance of it .
\end{abstract}

\section{Method and Hypothesis}

As a doctrinal qualitative research based on extensive survey of secondary data and literature, methodologically, with adoption of paradigm of descriptive interpretation, this research hypothesizes that the discussions and discourses over AI are biased, hold a serious lacuna thus need to be reconstructed to make it balanced and build better world than to browbeat people.

\section{KEYWORDS}

Artificial Intelligence, Human Future, Economic Development, Job Market

\section{BACKGROUND}

Everywhere and undisputedly, development is the first need of people. Nonetheless, development is not always an exclusively reserved responsibility of any single component of nation. The integrated efforts from all stakeholders- i.e. from leader to commoners and from professionals to public- are must. From savage to agrarian age too, the cycle of development had an appreciative pace. Following Greek civilization about 1000 BCE, subsequent Roman, Hwang-Ho, Mesopotamia and Indus valley civilizations had some spectacular and formative development initiations. Water Mill, Geometry, Steam engines were some achievements to note as those were accomplished to extend imperial leverage in the time and later too. But development in last 100 years was so radically miraculous that reconfigured the entire human-lives at the height of never imagined ease and comfort. The graph the world charted out in entire epoch of time has proved 
International Journal of Artificial Intelligence and Applications (IJAIA), Vol.10, No.2, March 2019

that we cannot not to progress. Thus pace of progress has always remained perpetual and unstoppable mission in the world.

\section{Progress, A Perpetual Task}

Human imagination and creative faculty have made all these miraculous changes possible. Authoring a book 'Simulacra and Simulation', an iconic philosopher, Baudrillard (1981) argues that imagination is the hyper-reality. Various ancient mythological books from Hindu, Islam and Buddhist sects too imagined airbus, telephone, ships and many of modern days' advancements. Once, modern science materialized them, human-lives began experiencing sea long changes. As the most unique invention of time, Graham made telephone in 1876 AD. Radio by Marconi in 1901, television by Baird in 1925 and computer by Eckert \& Mauchly in 1938 were new cum electrifying episodes of the series. Subsequently, ATM, Internet, Rocket, Genetic-Engineering, Washing Machine, Electric Bulb, Airbus, Ship, Cable Car, I-pad and Tablets and others are on show now. Hope many more are on the way and scientists may be robustly working for it.

Humans' undefeatable efficiency and unbeatably unique talents made all these developments possible. On the top, lately, wave of artificial intelligence (AI) has commanded a mammoth popularity. AI has surpassed the ever projected limitation of human discovery and invention in scientific filed. Human sense enabled robots are justifying it as they work like human minds. Writer of 'The Complete Problem Solver', Hayes (2013) believes AI as the divine pill for all the problems. Lately the self-regulated vehicles, weapons, agrarian equipments, and machines are on use, globally. Recently, Fukoku Life, an insurance company in Japan has replaced a significant quarter of human resource with robots. A hotel therein simulated same, last year.

Owing to such radical changes that AI has bestowed to the human lives, academicians too have commenced making commendable viewpoints on it, globally. Bostrom (2016) defines AI as "a system that can do all that a human intellect can do but much faster" (page: 64) and further as "a system composed of a large number of smaller intellects such that the system's overall performance across many very general domains vastly outstrips that of any cognitive system" (page: 65). Therefore it is easy to perceive that intelligence, which the machines have automated, is both super and faster than collective intelligence of entire human beings. Further rating AI as quality super-intelligence, he adds, "a system that is at least as fast as a human mind and vastly qualitative smarter" (page: 68).

Many of recent changes and developments have sufficiently worked to supplement the assumption. A robot called Pari at SBI bank, Darbarmarga branch in Nepal acts like receptionist. Many of south Asian nations like Bangladesh, Bhutan, Sri-Lanka, India and Pakistan have been highly lured and hugely infatuated at added and extended usage of such mechanically inbuilt intelligence in human maneuvers. Banks, call centers, restaurants and hotels, and shopping mall are few of sample institutions heavily incorporating it. Soon, robots are likely to largely replace humans in many functions and ensure the robot revolution. Among robot companies, Android Love Doll, Sexbot and To Companion are said of endeavoring in making robots that can walk, talk, understand human sense cum emotion and even can make sexual relation too. Such success and implication of AI sounds breathtaking to listen. But AI-induced real challenges will be beyond capacity to bear. 
International Journal of Artificial Intelligence and Applications (IJAIA), Vol.10, No.2, March 2019

\section{TOUGH TO BEAR}

AI is likely to ruthlessly plunge people into pool of vast challenges, in every nook and corner of the world. In Global Catastrophic Risk (2008), Bosterm and Ćirković (2008) count AI as fatal and grotesque as environmental degradation, terrorism, starvation, drug addiction, cold and civil wars and so on of these days. Minsky's (1986) The Society of Mind too cedes same.

AI, at the optimum of uses, severely damages the employment sector and creates gruesomely weird and bizarre state in job market. Even till the date, many people have irreparably missed jobs because of software and machines while marching to machined-based economy from muscle-based form alike argued by Bovee et al (2013), lead and highly cited authors on business communication. Of ongoing usual organizational practices too, an intercom system in telephone replaces two receptionists at a time whereas the tally software replaces 3 accountants. Now 4 to 5 people can smoothly operate a bank branch instead of plus dozen, needed a decade ago. Once machines are made with better human intelligence, the employment situation further deteriorates and it has already taken a substantial speed.

Some latest reports make hint that $\mathrm{AI}$ is likely to substitute $38 \%$ jobs in America, $35 \%$ in Germany, $30 \%$ in UK and $21 \%$ in Japan respectively till 2035. From 56 percent in transportation, 46 percent in manufacturing and $9 \%$ jobs in education sectors respectively shall be substituted. The trend can no way be withheld and aborted further. Following unending and egregious employment crisis, people lose economic status. Then, accruing and unbridled financial crunch frustrates people fathomlessly. People go bound in looting, murdering, smuggling and committing other criminal acts for livelihood. Selling properties and migrating to cheaper countries for easy life becomes rife. Trans-border criminalities become common. Organic human memory efficiency scales down a lot. Humans may be posed into dangers of being the house hold pets.

As everything becomes mechanic, demand of electricity jumps up approximately 40 times, leading severe energy crisis. Aftermath of frustration, people might detach from social and family responsibilities. Lethargy, family disintegration, decline on birth-rate, oversized expansion of negative mentality are highly possible. It might breach the pace of prosperity and wreck the reproduction pattern to further wax dismay and decay in human life cycle, globally.

Reports reveal that people can't have jobs plus 15 hours a week and that can't afford minimal subsistence too. Owing to excessive undercut on people's consumption capacity, producers go dashed-off to the dust and companies may turn bountifully bankrupt. Excessive uses of machines seriously plunder security concerns of countries and key information may be clandestinely stolen. Past episodes of cyber attack are burning examples. Right to secrecy shall be violated. And ruthless and aggressive plundering over others' resources for living may take an unchecked speed.

Currently, Google undergoes 40 thousand searches per second, reports reveal. On the top of dismay, the optimal level of AI encumbers internet million times more than today; and perhaps internet slumbers then ceases to function. Issues to be discussed, developed and designed backed with human rationality, relativism of truth, doctrine of necessity can never be well surmounted by machinery calculation, which is more robotic and based on given commands. Then, mechanical anarchism governs all sans being seconded by any other; and learning by mistake fully fails. No 
International Journal of Artificial Intelligence and Applications (IJAIA), Vol.10, No.2, March 2019

trial and error can be warranted; rather mechanic chaos and bedlam disgustingly bedeck the society. AI equipped machines can't be normally afforded.

Alike two World Wars destroyed human lives in earlier centuries, now AI and its boundless application can mar us again. Quest of economic development may be profoundly derailed and dwindled. Though AI is an epitome of much touted advancement now, it is sure to afflict humans endlessly, and some disgusts have been already germinated. The first and big impacts will be on economy of people, further generating heavy havoc in all aspects. Such trends are heavily discussed and projected into various contemporary literatures. Scholars have profoundly expressed woos and worries about the future that AI disgustingly leads towards sordid darkness. A plethora of discourses and counter discourses is 'recent and fashioned academic contributions' in regards to AI.

\section{Discourses And Counter Discourses}

A study jointly ventured by Frey and Osborne (2013) has alarmingly pointed out that US is hellishly squeezed and is likely to losing 47 percent of existing total employments owing to extremity of computerization. In contrary of it, Autor (2015), though denies admitting about obstruction on human intelligentsia and labor because of automation and technological progress, nonetheless dares not to argue that AI won't emasculate and weaken the economic life cycle of people. Bresnahan et al (2002) strongly believe that advanced computerization can only substitute the 'middle-skills employees' thus poses no negative leverage on human brains however Van Reenen (2011) still feels a dearth and acute shortage of rigorous studies to explore AI related lethal leverages and impacts on human lives and pace of progress. Presenting it as an 'unpredictable and unintended side effects of uncontrolled innovation', Bostrom (2014) coins a beautiful phrase 'household pets' to indicate the human condition ahead. Hence, he alarmingly alerts people to siphon off adequate measures before it is too late to lament but guides no concrete ways to do so.

Russell \& Norvig (2010) stress to instill some human values in robots hence AI shall be in compliance with ethics whereas Wallach \& Allen (2008), prior to them, had projected the notion of 'inbuilt ethical programme' to overcome Yudkowsky's (2008) projection of AI-induced 'existential risk' alike to perception of Acemoglu and Autor (2011), who pressingly paid pressure on 'indigenized automation of technology'. Bloom et al (2005) urge that AI might simulate innovation that takes low level acceleration at the advent but gear up to the excessive high speed at the final stage. However, the same may be detrimentally discouraging to the expectation of progress and prosperity at the end. Further, Agrawal at el (2017) regard it as 'recombinant growth' along a transition path. To certify the miracle making marvelous mystery of AI, Autor et al (2003) take self-driving car and modern scientific lab as the latest reform whereas Baslandze (2016) believes on knowledge diffusion and sectoral relocation to adduce so as there is no sector where AI can be negated or even seconded.

A notion of 'Approach to automation' by Peretto and Seater (2013) and 'Robots at Work' by Graetz and Michaels (2015) too unfold mercilessly negative impacts that AI is going of crown upon the rest entire human society. Still, since not being subject of immediate assimilation, the nature of advanced realization is not sensed into the degree as it had to be. Tirole (2017) believes the wage gap between skilled and semiskilled to be skyrocketing ahead because of advanced development of AI. Even middle men can accomplish on performing monitoring jobs spotlessly 
International Journal of Artificial Intelligence and Applications (IJAIA), Vol.10, No.2, March 2019

as Zeira (1998) astonishingly makes an overrated response that AI has profoundly caused a paradigm shift in real life and day to day occurrences and incurrence of people. He confirms that AI has taken people to the realm which was beyond imagination till some centuries back.

AI, as an impassioned activity of human, begins to groom machines intelligently equipped with rare foresight and vision as well, Nilsson (2010) rates. Corduck (2004) feels it as thinking machine whereas Calo (2010) believes it as a human endeavor to make humans themselves fake or so fake either; he but sarcastically remarks that that elephant can't dance in order to point the eventual limitation of AI. Taking things at further worse, Bostrom and Ćirković (2008) urge that AI has not only failed to assimilate and negotiate the philosophical lacuna but also it incurs some unstated serious technical failure as well, what for authors have said 'two informal fuzzy categories'. Bamberger and Mulligan (2015) unfold a grotesque and seemingly obnoxious attack on privacy of people because of heightened attachment to the mechanically controlled and subdued lives whereas Jaynes (2003) worries on confusing state of knowledge and opinions that AI has been capaciously crediting amongst human begins and calls it 'mind projection fallacy'. Thus Minsky (1986) believes AI not to be friendly as people are astonishingly paying subservience at; rather it is definitely sure to drive off away lots of opportunities and ideas from people. Similarly, Yudkowsky (2008) scares on lack of abstract intelligence on AI as mechanical computation and command merely works on acute and straight blindness with ditto repetition without having understanding about theory of necessity or doctrine of urgency. Therefore, Bostrom (2004), expressing woes as that rest of others discussed issues are mere wee, worries on weird problems that AI may woo people in restraining or detaching from reproduction system because of excessive engagement with machines. That will severely lounge the world back in manifolds.

To reflect the generic function of AI, Goertzel and Pennachin (2006) call it Artificial General Intelligence since it can't have specific and technical functions which demand volume of theory of necessity and comparative analysis. Agreeing with similar notion, Kamm (2007) perceives it as impermissible to do things on its own sake as humans' control and command might change it heavily on its working procedure. Despite having many limitations and inabilities to entirely swap the human intelligence, this latest scientific and progressive brain child of human minds, AI can pose some serious cum lasting effects as Omohundro (2008) believes; and on the same note Yudkowsky (2008) calls it positively negative factor. Highlighting its limitation, Bloom (2013) notes of gross and grim failure to share and embody 'genetically programmed moral values' and projects it as mere baby of evil till now. The very painful and soaring situation is 'treacherous turn', in words of Bostrom (2014).

Therefore, Davis (2015) seriously urges for design of 'machine ethics', which shall probably be a new branch of ethics that could crucially assist to operate machine into ethical manner as well as to protect humans from vast ocean of dangers and angers, for safety of both AI and human. His overture commands ground on a conservatively rough calculation made by Hall (2008) as to AI is prone to outplace world economy of 7 billion people together with serious impacts on natural resources and physical capital. In line with those authors, Russell et al (2003) propose to revisit our attitude at anthropoids as that will not be as mesmerizing and glamorizing as we are overrated and been wrongly presuming. Ergo the clock-speed difference between biological and digital mind, assumed by Sotala (2012), defiantly proves and places AI in grossly slow and sluggish in area of subjective analysis. 
International Journal of Artificial Intelligence and Applications (IJAIA), Vol.10, No.2, March 2019

Despite having some obnoxious and outrageous responses, Kaplan (2017) positively perceives AI to manumit a blessed contribution on 'elderly care and retail shopping' and Michael (2015) overrates it for possibly inexplicable importance in domain of crime curtailing and investigation. Here, Acemoglu (2003) is spurred to motion that owing to infinite penetration and implication of technology on people, who will be heavily dwelling on digital world, there shall be an inexplicable inequality bolstered and boosted by AI. Similarly Autor and Dorn (2013) again scare to have a new episode of American dominance and hegemony since most of AI appliances, which shall be produced and percolated, undergo compliance to American obsession and wishes. Based on same fear, Brynjolfsson and McAfee (2014) worry about declining wages as the next detrimental upshot of AI in array; and further, Joshi and Roh (2009) too express deep concern on deteriorating human values and family attachment because of AI.

A study by Arntz at el (2016), for the Organization for Economic Co-operation and Development (OECD), refuses to believe the 47-percent estimate regarding the jobs likely to be replaced by AI. Their tentative calculation exceeds the prior set limit and makes a hint to affect about 67 percent in total. Moreover, Autor (2015) claims that even the remaining will be still the subject of research whether those last long. But Barocas and Selbst (2016) expect AI not being capacitated to cause full-swing swapping as it only works on data which are trained to be computed. Nonetheless, alike other authors, Cherry (2015) too deeply worries as that the heavy effect and blow of this advancement will be on micro-workers of routine based manual workers on jobs of repetitive nature. In series, Davis and Osoba (2016), with their studies on health data privacy and consumer fairness, note that there are many toxically affected and suffocated diseases on human bodies because of AI.

In addition of aforementioned studies, Jaimovich and Siu (2012) draw and drill a distinct line of separation that AI is likely to impact. They opine that routine jobs shall be evidently and manesifestedly under marked risk whereas cognitive occupation framework still demands critical creative human faculty to be surmounted; and for the same, Andrew (2016) rates it as 'limit of AI automability'. As Paul (2010) feels the privacy to be broken and plundered to the great pool because of AI largely taking health data and consumer fairness under its undue leverage, Wystrach (2013), Lyng (2004) and Tzafestas (2016), in their different studies, heavily delve into very discourse and conclude that AI can definitely be depositing the devastating damages on economic lives of majority of people though few of technocrats remain unstained and untarnished with this evident pain. Leaving entire humans in total disarray and bizarre, AI turns to be brazen mockery of human insight and intelligence rather. They urge that it shall be nauseatingly irresponsible to perceive that AI's impacts can be stymied by resorting to some other recourse rather.

Sorokina (2015) feels AI as deep learning but more concerned into the area of large data sets whereas Crawford (2016) rates it as 'white guys problem' as that is not exponentially advanced to the grass roots of people in non-western technologically moderate or median societies. Though having such an intensive discussion on behalf of many of noted scholars of time, it is fairly seen lopsided as there is a serious lacuna in course of building balanced view points and positive approach regarding studies on AI.

\section{SERIOUS LACUNA}

Though many authors are expressing deep concern over grotesque future AI is likely to pose- 
International Journal of Artificial Intelligence and Applications (IJAIA), Vol.10, No.2, March 2019

compared to very minimal scholars who seem seemingly positive towards the arrestingly spectacular development at the time- there is wondering gap on penning the positive efforts. Hardly, eloquently and unequivocally, anyone at all has guided the ways to overcome the challenge. They are all busy bodies and active minds to instill negative worldview and further browbeat and cow the people. Every scientific innovation has both aspects as pain and pleasure. But the academic exercise has to penetrate more on finding the suitable solutions to minimize the challenge and mitigate the harms it may generate.

As an evident exception by lodging reverse standpoint than above refereed authors, Pavaloiu (2016) poses convincingly positive notes and writes, "AI can solve the unsolvable problems. People need to be part of its development in order for AI to help augment human ingenuity and create a culture based on collaboration" (page: 23), hence assimilates the indispensible credit that AI can confer to the society. Lewis et al find (2014) full rationality in argument; and Kurzweil (2005) too calls it singularity of truth as scaring of its hellish and pestilential outcomes ahead can neither and nowhere drive us into any pleasing position. Hence, maximizing the benefits and negotiating with the falls that we are destined to incur- sans any pangs of bereavement and anxiety- is one and only the rational road ahead. But there is serious and acute dearth of such scholars who dare to foil and defrost the one-way created discourses then make societies hopeful over AI or orient people to use if for noble cause of human welfare.

If sought and searched, AI can be of profoundly productive for noble cause of mass welfare and development. Earning money, promoting security, effectivizing human lives, and harnessing many other multiple benefits can be projected or peeped in. Despite possibility, there is no little or no effort at all paid to identify this noble action. As the suffering to society cannot be tolerated at any alibi, the one and only the quest of human minds' engagement over any issue should to explore the ways for saving humankinds and taking society at new height of progress and prosperity.

Simply discussing about harrowing and agonizing frustrations will fuel no positive symptoms. It is neither helpful to society not it gets any sanction as an engaging academic pursuit. Any academic pursuit should be for positive development and progress of the society ahead. It should create hope; and it should know, go then show the path of optimism for the people.

\section{Conclusion}

So further researches and explorations are matter of the urgent need to offer panacea over such menacing academic mis- exploitation what is driving societies towards negative direction. Only digging the deplorable and dingy or lethal future is no way corrective course for society than being mere provocative to people. Thus, leaving the existing trend of producing discourses with arguments and counter arguments to discover the loss or detriment it possess, the appreciative academic move to handle it ought to be in to the academic quest of people. The analysis till the time seems lopsided, pessimist and only the negative worldview provoking enterprise. Such pleasure can never be a true spirit in purview of appreciative academic enthusiasm. Thus a full clock reverse in this trend is needed. Scholars should aware people to mitigate and take AI created challenges. Orienting readers to use AI to support the human lives and economic health of people remain intact or make more salubrious and vibrant should be their one and only aim. But having no progress on it and only producing literature to heavily expose the challenges and demerits of AI, thus building overarching pessimism on people, indicate a flat and far 
International Journal of Artificial Intelligence and Applications (IJAIA), Vol.10, No.2, March 2019

inconsolable and in-concealable lacuna in existing discourses and counter discourses over Artificial Intelligence.

\section{WORKS Cited}

[1] Acemoglu, Daron. (2003). "Directed Technological Change." Review of Economic Studies 69(4). P+ 781-809.

[2] Acemoglu, Daron and Autor, David. (2011). "Skills, Tasks and Technologies: Implications for Employment and Earnings." Handbook of Labor Economics, Vol. 4. Edited by Ashenfelter and D. Card. Elsevier, P+ 1043-1171.

[3] Agrawal, Ajay, John McHale and Alex Oettl. (2017). "Artificial Intelligence and Recombinant Growth." Manuscript. Canada: University of Toronto.

[4] Andrew, Ng. (2016). "What AI Can and Can't Do." Harvard Business Review. November, 2016.

[5] Arntz, M., T. Gregory and U. Zierahn. (2016). "The Risk of Automation for Jobs in OECD Countries: A Comparative Analysis." OECD Social, Employment and Migration Working Papers, No. 189, December.

[6] Autor, David H. (2015). "Why are There Still So Many Jobs? The History and Future of Workplace Automation." Journal of Economic Perspectives, Vol. 29, No. 3. P+ 3-30.

[7] Autor, David H. and Dorn, David. (2013). "The Growth of Low-Skill Service Jobs and the Polarization of the US Labor Market." American Economic Review 103(5): 1553-97.

[8] Autor, David H., Frank Levy and Richard J. Murnane. (2003). "The Skill Content of Recent Technological Change: An Empirical Exploration.” The Quarterly Journal of Economics. November 2003, 118 (4), P+ 1279-1333.

[9] Bamberger, Kenneth A. and Mulligan, Deirdre K. (2015). Privacy on the Ground: Driving Corporate Behaviour in the United States and Europe. Cambridge, Massachusetts: MIT Press.

[10] Barocas, S. and Selbst, A. D. (2016). "Big Data's Disparate Impact." California Law Review, Vol. 104.

[11] Baslandze, Salome. (2016). "The Role of the IT Revolution in Knowledge Diffusion, Innovation and Reallocation." EIEF manuscript.

[12] Baudrillard, Jean. (1981). Simulacra and Simulation. Translated by Sheila Faria Galser. USA: Michigan.

[13] Bloom, P. (2013). Just babies: the Origins of Good and Evil. New York: Crow.

[14] Bloom, Nick, Richard Blundell, Rachel Griffith and Peter Howitt. (2005). "Competition and Innovation: An Inverted-U Relationship." The Quarterly Journal of Economics. USA: MIT Press, May, 120 (2), P+ 701-728.

[15] Bostrom, N. (2004). "The Future of Human Evolution." Death and Anti $\square$ Death: Two Hundred Years after Kant, Fifty Years after Turing. Edited by Charles Tandy \& Palo Alto. California: Ria University Press.

[16] Bostrom, N. (2014). Superintelligence: Paths, Dangers, Strategies. New York: Oxford University Press.

[17] Bostrom, N. (2016). Superintelligence. New York: Oxford University Press.

[18] Bostrom, Nick and Ćirković, Milan M. (2008). Global Catastrophic Risks. New York: Oxford University press.

[19] Bovee, Courtland and Thrill, John V. (2013). Business Communciation Today. USA: Pearson.

[20] Bresnahan, Timothy F., Erik Brynjolfsson and Lorin M. Hitt. (2002). "Information Technology, Workplace Organization, and the Demand for Skilled Labour: Firm-Level Evidence." Quarterly Journal of Economics, Vol. 117, No. 1. P+ 339-376.

[21] Brynjolfsson, Erik and McAfee, Andrew. (2014). The Second Machine Age: Work, Progress, and Prosperity in a Time of Brilliant Technologies. USA: WW Norton \& Company.

[22] Calo, M. Ryan. (2010). "People Can Be So Fake: A New Dimension to Privacy and Technology Scholarship." Penn State Law Review 114, no. 3. P+ 809-855. 
International Journal of Artificial Intelligence and Applications (IJAIA), Vol.10, No.2, March 2019

[23] Cherry, M. A. (2015). "Beyond Misclassification: The Digital Transformation of Work." Comparative Labour Law Journal \& Policy Journal, Vol. 37, 2015. P+ 577.

[24] Corduck, Pamela Mc. (2004). Machines Who Think: A Personal Inquiry into the History and Prospects of Artificial Intelligence. San Francisco: Natick, MA: A. K. Peters.

[25] Crawford, Kate. (2016). "Artificial Intelligence's White Guy Problem." New York Times, June 25.

[26] Davis, E. (2015). "Ethical Guidelines for a Super-intelligence." Artificial Intelligence, 220. P+ 121124.

[27] Davis, John S. and Osoba, Osonde A. (2017). Privacy Preservation in the Age of Big Data: A Survey. Santa Monica, Calif.: RAND Corporation, WR-1161.

[28] Frey, Carl Benedikt and Osborne, Michael A. (2013). The Future of Employment: How Susceptible Are Jobs to Computerization? USA: Oxford Martin School.

[29] Goertzel, B. and Pennachin, C. (2006). Artificial General Intelligence. New York, NY: Springer $\square$ Verlag.

[30] Graetz, Georg and Michaels, Guy. (2015). "Robots at Work." CEPR Discussion Paper, No. 10477.

[31] Hall, J. S. (2008). Engineering Utopia." Frontiers in Artificial Intelligence and Applications, 171, 460.

[32] Hayes, John R. (2013). The Complete Problem Solver. USA: Routledge.

[33] Jaimovich, Nir and Siu, Henry E. (2012). The Trend is the Cycle: Job Polarization and Jobless Recoveries (Working Paper 18334). Cambridge, Mass: National Bureau of Economic Research.

[34] Jaynes, E. T. (2003). Probability Theory: The Logic of Science. Edited by G. Larry Bretthorst. New York: Cambridge University Press. doi:10.2277/0521592712.

[35] Joshi, Aparna and Roh, Hyntak. (2009). "The Role of Context in Work Team Diversity Research: A Meta-Analytic Review." Academy of Management Journal (52). P+ 599-627.

[36] Kamm, F. (2007). Intricate Ethics: Rights, Responsibilities, and Permissible Harm. Oxford: Oxford University Press.

[37] Kaplan, J. (2017). "Artificial Intelligence: Think Again.” Communications of the ACM (60). P+ 3638.

[38] Kurzweil, R. (2005). The Singularity is Near: When Humans Transcend Biology. USA: Penguin.

[39] Lewis, R. L., A. Howes \& S. Singh. (2014). "Computational rationality: Linking Mechanism and Behaviour through Bounded Utility Maximization.” Topics in Cognitive Science, 6(2). P+ 279-311.

[40] Lyng, S (2004). Edgework: The Sociology of Risk-Taking. London, UK; New York: Routledge, Taylor \& Francis Group.

[41] Michael, G. (2015). “The Future of Artificial Intelligence: Benevolent or Malevolent?" Skeptic, Altadena, CA. P+1: 57

[42] Minsky, Marvin. (1986). The Society of Mind. New York: Simon \& Schuster.

[43] Nilsson, Nils J. (2010). The Quest for Artificial Intelligence: A History of Ideas and Achievements. Cambridge. UK: Cambridge University Press.

[44] Omohundro, S. (2008). "The Basic AI Drives." Proceedings of the AGI $\square 08$ Workshop. Amsterdam: IOS Press. P+ 483 $\square 492$.

[45] Paul, Ohm. (2010). "Broken Promises of Privacy: Responding to the Surprising Failure of Anonymization". UCLA Law Review, Vol. 57, P+ 1701.

[46] Pavaloiu, A. (2016). "The Impact of Artificial Intelligence on Global Trends." Journal of Multidisciplinary Developments, 1(1). P+ 21-37.

[47] Peretto, Pietro F. and Seater, John J. (2013). "Factor-eliminating Technical Change." Journal of Monetary Economics, 60 (4). P+ 459-473.

[48] Russell, S., \& Norvig, P. (2010). Artificial Intelligence: A Modern Approach. New Jersey: Pearson.

[49] Russell, S. J., P. Norvig, J.F. Canny, J. M. Malik, \& D. D. Edwards. (2003). Artificial Intelligence: A Modern Approach (Vol. 2). Prentice Hall: Upper Saddle River.

[50] Sorokina, O. (2015). Artificial Intelligence in Social Media: What AI Knows About You, and What You Need to Know? Hootsuite Social Media Management

[51] Sotala, K. (2012). “Advantages of Artificial Intelligences, Uploads and Digital Minds.”International Journal of Machine Consciousness, 04(01), P+ 275-291. doi: 10 .1142/S1793843012400161.

[52] Tirole, Jean. (2017). Economics for the Common Good. USA: Princeton University Press. 
International Journal of Artificial Intelligence and Applications (IJAIA), Vol.10, No.2, March 2019

[53] Tzafestas, S.G. (2016). Roboethics: A Navigating Overview. Berlin: Springer.

[54] Van-Reenen, John. (2011). "Wage Inequality, Technology and Trade: 21st Century Evidence." Labour Economics, Vol. 18, No. 6. P+ 730-741.

[55] Wallach, W., \& Allen, C. (2008). Moral Machines: Teaching Robots Right from Wrong. USA: Oxford University Press.

[56] Wystrach, A. (2013). "We've been Looking at Ant Intelligence the Wrong Way." Scientific American, 30 August.

[57] Yudkowsky, Eliezer. (2008). "Artificial Intelligence as a Positive and Negative Factor in Global Risk." Global Catastrophic Risks. Edited by Nick Bostrom and Milan M. Ćirković. New York: Oxford University Press, P+ 308-345.

[58] Zeira, Joseph. (1998). "Workers, Machines, and Economic Growth." Quarterly Journal of Economics, November 113 (4). P+ 1091-1117. 